\title{
VISIBILITY OF SUSTAINABILITY: THE MAKING OF THE ITINERANT PAVILION 'SUMMERLABB'
}

\author{
S.P.G. MOONEN \\ Department of the Built Environment, Eindhoven University of Technology, The Netherlands.
}

\begin{abstract}
To intrinsically motivate students by challenging concrete tasks is an effective way of learning - and in particular, if the task is intended to deliver a tangible outcome. Bearing this in mind, a challenging Problem Based Learning assignment for Master students of TU/e was found in developing a sustainable pavilion for festivals in cooperation with a third party (Double2). Many (music) festivals nowadays go on the message of sustainability in addition to their core business of 'music and food'. This can offer a very challenging assignment; to develop an iconic object that stands out in a large-scale event and by making sustainability tangible to a large audience. The aspect of designing a temporal and original creation is already challenging, yet it becomes integral ('Research by Design') by involving practical requirements that have to be met too regarding safety aspects, fast and practical assembling, et cetera. And by actually building a full-scale creation makes this project exceptionally, being the proof of the pudding of the creation as well as the icing on the cake for all involved (and a special item for a students' portfolio). Making prototypes and considering details on different scale levels ('learning by doing') is very instructive for students who study buildings. And helping to assemble the pavilions on a festival and support the set-up on location ('learning by precedent') is highly enlightening, too.

This paper describes the 'Summerlabb' project of developing a number of structures as itinerant exhibition at festivals and events that were developed in analogy with earlier design projects where student teams were involved.
\end{abstract}

Keywords: integral design, PBL, problem based learning, proof of concept, visibility of sustainability.

\section{INTRODUCTION}

In 2013, a third party called 'Double2' approached Eindhoven University of Technology (TU/e) with an unusual question for students to design an iconic pavilion to express sustainability on (music) festivals. A practical assignment for students is, in itself, not unusual in the Bachelor and Master programme of TU/e's Department of the Built Environment (BE@ TU/e) as both programmes focus on multidisciplinary design [1]. However the complexity and the scale of this design assignment are quite special (in architectural, technical, construction, and usability perspective).

The specific question of Double2 was to design a versatile pavilion that provides exhibition spaces for frontrunners of sustainable innovations to present their most striking outcomes on festivals. The particular challenge to the students was not only to design exhibition space but also to develop a pavilion that is a showcase on sustainability. The result is the 'Summerlabb'-pavilion; an assembly of 18 structures, where each structure exhibits different facets of sustainability on full scale such as bio-based materials, reusing waste, reducing transport, new use of plastic waste, and much more. This students' design is awarded the STW-Design price 2014 [2] and Woodchallenge 2014 [3].

\section{STUDENTS' DESIGN PROCESS}

The assignment to design a 'Summerlabb' pavilion was the subject of study in a design studio in the Master course of the Architecture track of Architecture, Building \& Planning (a multidisciplinary Master at BE@TU/e). 


\subsection{Design studio}

The studio had 13 students (Fig. 1). All students were asked to develop concepts for the itinerant exhibition at festivals and events [4]. Some students preferred to work as individual; others preferred to work in a small team of maximum three students. Students were free to work independently or to form a team (or even to change the composition of the team during the semester). At the end of the semester there were six individual designs, two two-student teams, and one three-student team.

The studio work started by a presentation of the commissioning third party (Double2) who explained the need for a versatile design, and explained the circumstances of building at a festival site. They also sketched the different partners with their extraordinary novelties and with specific needs regarding exhibition spaces on festivals. All partners are frontrunners of sustainable innovations, and can be start-ups as well as multinationals and educational institutions [5]. Within the envelope of the pavilion, a considerable number of partners (up to 30) need exhibition spaces with various different types of set-ups to exhibit their new ideas and to enthuse visitors of the festival about sustainable innovations [6].

The design studio lasted for a full semester and resulted in nine different concepts. After this, the most appealing and feasible concept was selected by Double2 in close cooperation with the tutors of the studio. The selected pavilion was designed by Floor van Schie. The main idea was an ensemble of structures with the archetype shape of a Dutch house with a gabled roof. In the centre is a rising structure made by scaffolding that holds up some 'houses' to attract attention from a large distance. The ensemble was enclosed in the winning design by a wall composed out of waste that would be collected during a festival. (Fig. 2).

\subsection{Technical design}

Next, the chosen initial design had to be elaborated into real practical details. Materials of sponsors had to be integrated, too. And consultation with a construction company had to be

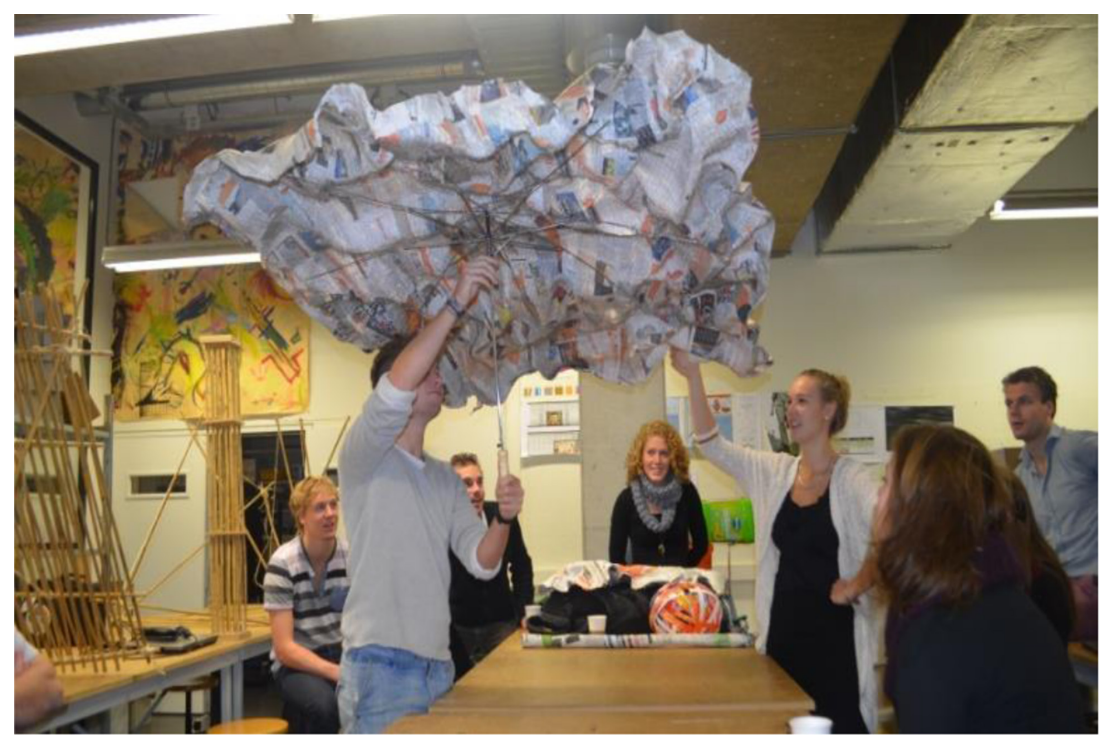

Figure 1: Students in the design studio demonstrating a prototype. 


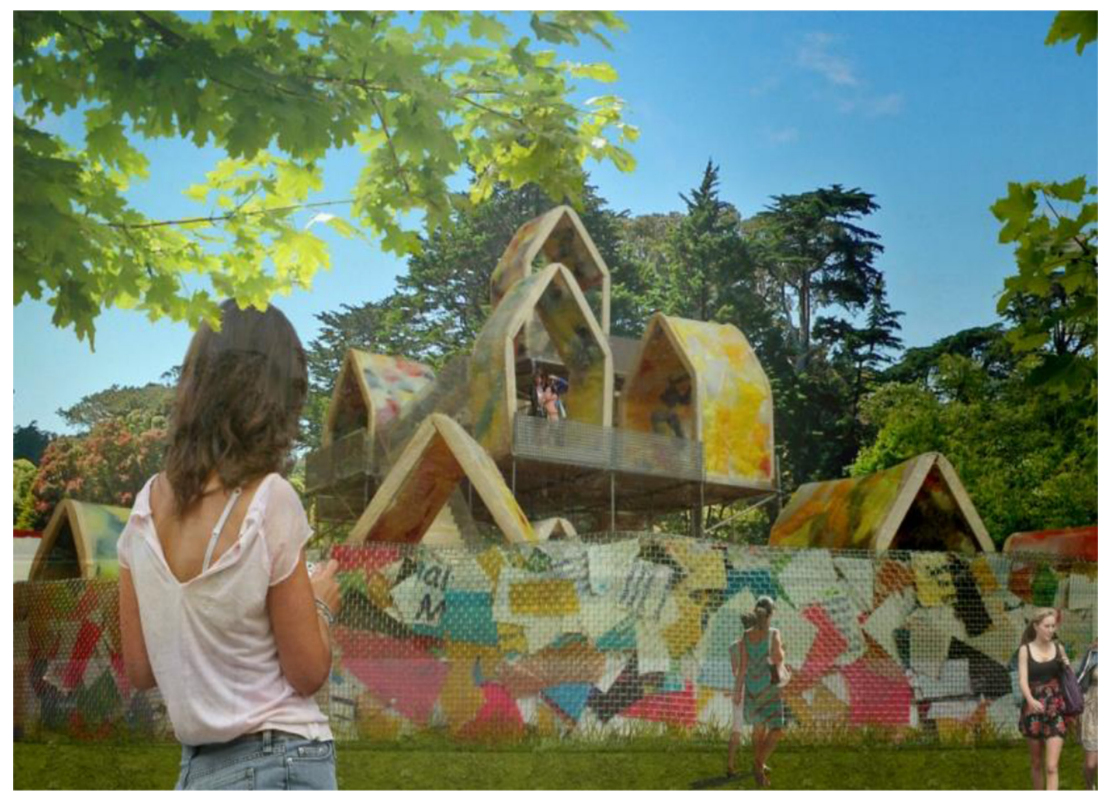

Figure 2: Winning idea of Floor van Schie for an itinerant pavilion.

organised. In this next phase, a group of three students was put together (the winning student Floor van Schie with two friends, Alice Janssen and Marthe Doornbos) who focussed on technical and practical issues. In this phase the concept of the surrounding wall made of waste from the festival itself was abandoned due to practical issues. And also because the structures (when placed in a circular pattern) already formed a masking of the area.

During the technical phase, the idea of making the structures in a foldable manner was brought in the design and was elaborated into a practical feature.

The three students were involved to raise funding as well as in making technical drawings, calculations, and fire safety calculations [7].

\subsection{Making of a pavilion with 18 foldable structures}

The construction phase started after three months of elaborating on technical issues and making a proof of concept for the folding structure. In this phase, the three students organised a group of in total 57 students for actually making the 18 structures of the pavilion [8].

Making these 18 structures took 21 days in total. The main construction material was timber (in total $38 \mathrm{~m}^{3}$ of Douglas pine was processed), connected to reclaimed old inner doors from demolition (in total 324 old inner doors were used). About 22.640 screws were needed to connect all elements as just one example of the extent of the work [9].

\subsection{Proof of the pudding is in the eating}

The pavilion was introduced on July 12th 2014 at the Dance festival Extrema Outdoor in Best, the Netherlands (Fig. 3). Here, a large scaffolding was built in the centre of the pavilion to 


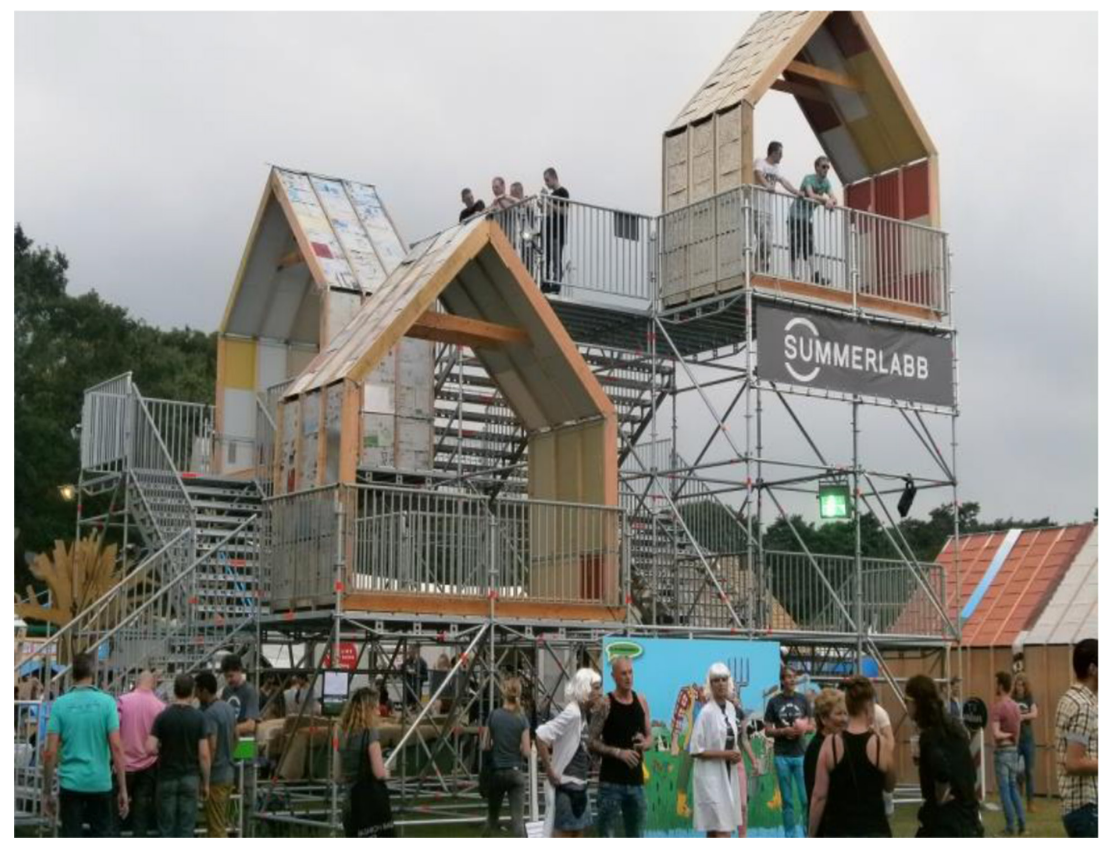

Figure 3: Tower supporting houses (Extrema Outdoor-Best 2014).

support three structures [10]. All other structures were placed in a circular set-up to providing exhibition space. With the assembly of the pavilion, all objects are in itself a showcase on sustainability, exhibiting facets of sustainability on full-scale with reusing waste, showing means to reducing transport, showcasing opportunities of bio-based materials, and more features.

After the festival in Best, the pavilion proved its value at many other festivals, like WereldHavenDagen in Rotterdam (5/7|9|2014, 4/6|9|2015, 2/4|9|2016), Eurosonic/Noorderslag in Groningen (14/17|1|2015), Pukkelpop in Hasselt-Belgium (20/22|8|2015), Dutch Design Week in Eindhoven (17/25|10|2015).

\section{EXHIBITION WITH A UNIQUE CONCEPT}

The Summerlabb pavilion is developed to promote sustainable innovations by the Summerlabb partners. The pavilion is created as an itinerant exhibition of versatile structures to offer exhibition spaces on large scale festivals and events. The Summerlabb partners range from start-ups to multinational corporations and educational institutions. Last year, there were over 50 partners involved in Summerlabb, in the Netherlands, all frontrunners in the field of sustainably.

\subsection{Summerlabb concept}

Double2 developed the Summerlabb concept in 2010 and improved it since then. This remarkable concept is all about sharing, challenging and exciting audience by using a unique system to promote sustainable innovations. This interactive approach connects festival-goers with enthusiastic researchers and entrepreneurs who pass on knowledge by enthusiastically one-on-one discussing about their stunning examples and researches. These partners share new ideas and products by looking, feeling, touching, tasting and smelling instead of the 
traditional passive way of knowledge transfer by posters, text and models. The ultimate goal is to give visitors a happy feeling and to increase a better understanding of sustainability with its importance towards securing a safe, healthy and prosperous society. Summerlabb is considered a never ending hotspot of sensible experiences offering a view into a future in which sustainable innovation and business are leading.

Summerlabb provides exhibition facilities to different partners. The exhibition renews on a regular basis on the basis of the needs and requirements of partners who are interested in a certain festival event. It is therefore possible to dedicate an exhibition to a specific theme, for instance energy, low carbon, material policies, et cetera. And as the pavilion is designed to iterate from one location to another, the set-up can be changed in many different ways, depending on a specific theme and the specific local circumstances.

\subsection{A pavilion to contribute to the discourse of the building industry}

The set of structures was designed to compel attention in a playful way to sustainable developments in the building industry. It is based on Summerlabb's effective way of communicating complex matter and issues to a large audience (for example modes of action to reduce carbon emission). This specific way of exhibiting makes the presentations suitable for visitors of all ages, technically skilled and non-technical visitors, experts and amateurs.

Central in this communication is the pavilion itself. It confronts visitors with sustainable concepts in an eye-catching way and alerts the public at large to the need to transform the building industry. In such, it contributes to the global sustainability discourse to reduce $\mathrm{CO}_{2}$ emission, reduction of energy-use, reduction of waste and re-use materials from demolition.

\subsection{Iconic design}

The structures of the Summerlabb pavilion are located around a tower, made of steel poles, beams, diagonals and stairs, making the tower an open structure with many platforms attached. Some of the structures are intertwined in the tower to be part of the walkway to the top of the tower (Fig. 4). This tower with structures attached to the platforms makes that the pavilion is an eye catcher and seen from a distance. As a result of the exclusive design of the tower, the Summerlabb exhibition stands out in any environment, even if there is a massive crowd.

The implementation of the design of the tower and structures is flexible and can be adjusted from case to case: the structures can be combined in many different configurations providing flexibility in exhibition formats, lay-out and requirements. In this way it accommodates a variety of partners with either large or small set-ups to showcase their newest sustainable innovations, ideas, and products.

\subsection{Combining forces}

Summerlabb creates an environment for its audience to pick up knowledge and have a look into the future. However Summerlabb is much more. It's also a creative hotspot, a meeting place for kindred spirits and a birthplace for new alliances that leads to novel, very surprising and brilliant projects and businesses. Preceding exhibitions demonstrated stunning examples of Summerlabb partners who normally operate on opposite ends of the production chain but found each other in surprising initiatives and novel business concepts. By combining 


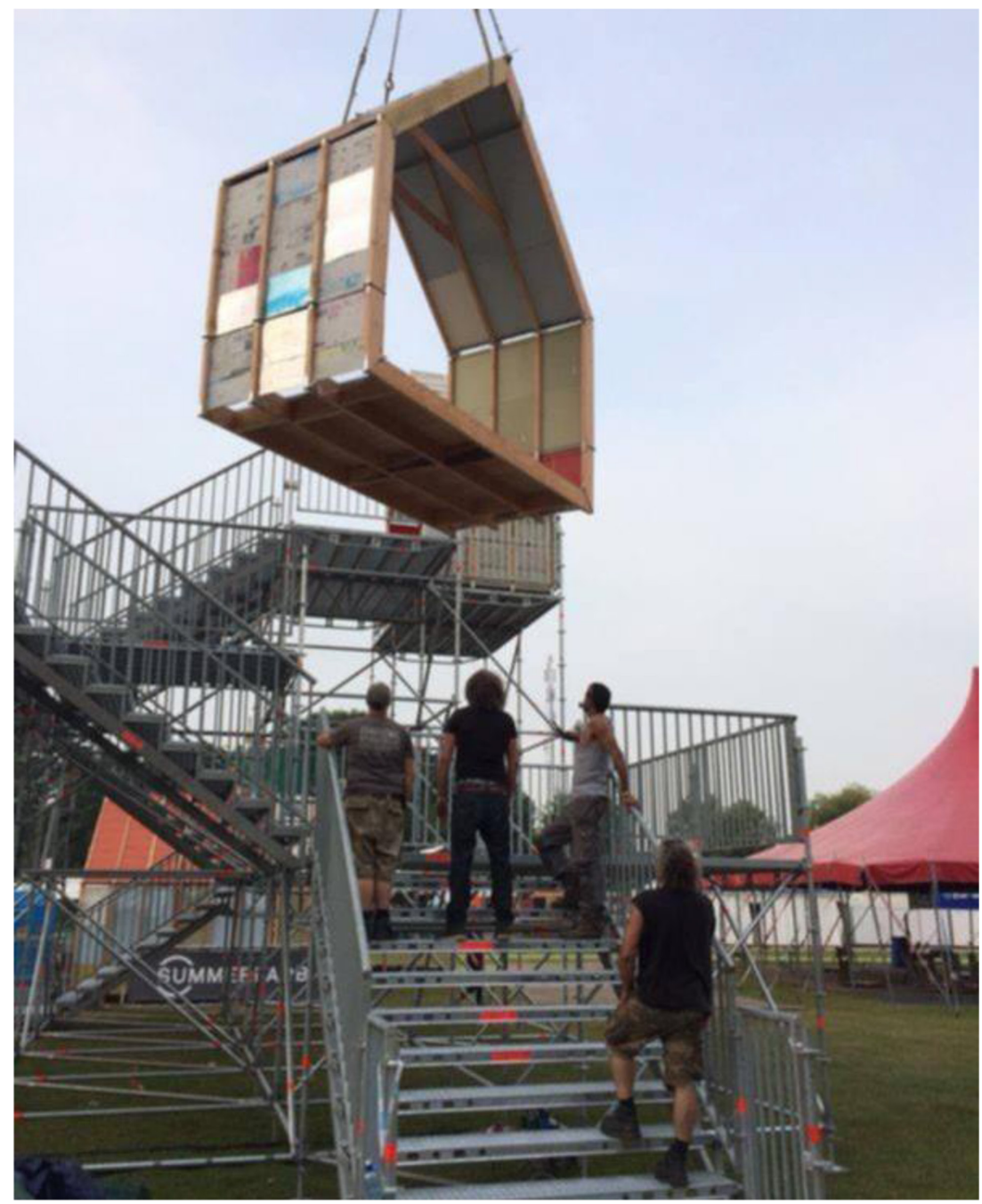

Figure 4: Placing a structure on the tower of scaffolding.

forces Summerlabb serves as a catalyst, new products have been developed and new trends initiated.

\section{MANY FACES OF SUSTAINABILITY}

Summerlabb uses its sustainability pavilion and platform as an exhibition for large scale festivals and events. The pavilion emphasizes that sustainability has many faces. Through this real-scale example, that brings together a mixture of unexpected solutions in a playful way, we will bring the significance of the need to change to a massive audience of large events.

The pavilion of Summerlabb is much more than just a shell to provide exhibition places. The pavilion itself is basically expressing about what happens inside; it is about sharing new ideas and products in a dialogue format with the audience under the roof of sustainable 
houses. In this way, the Summerlabb pavilion brings the dialogue of the faces of sustainable building to a next level by visualising many characteristics of sustainability.

Summerlabb confronts its visitors to create awareness and contributes to the global sustainability discourse. A change of attitude and appropriate actions are much needed, starting now. For example by showing a surprising and alternative use of plastic waste may enlighten visitors the beauty of waste.

The set-up of Summerlabb consists of a variable number of structures. Each structure requires five elements (Figs 5 and 6). These elements are made of timber from nearby forests. In between the timber are parts of re-sawn inner doors that are reclaimed from demolition. The elements are interconnected by hinges to create a foldable structure, with five panels put together. This

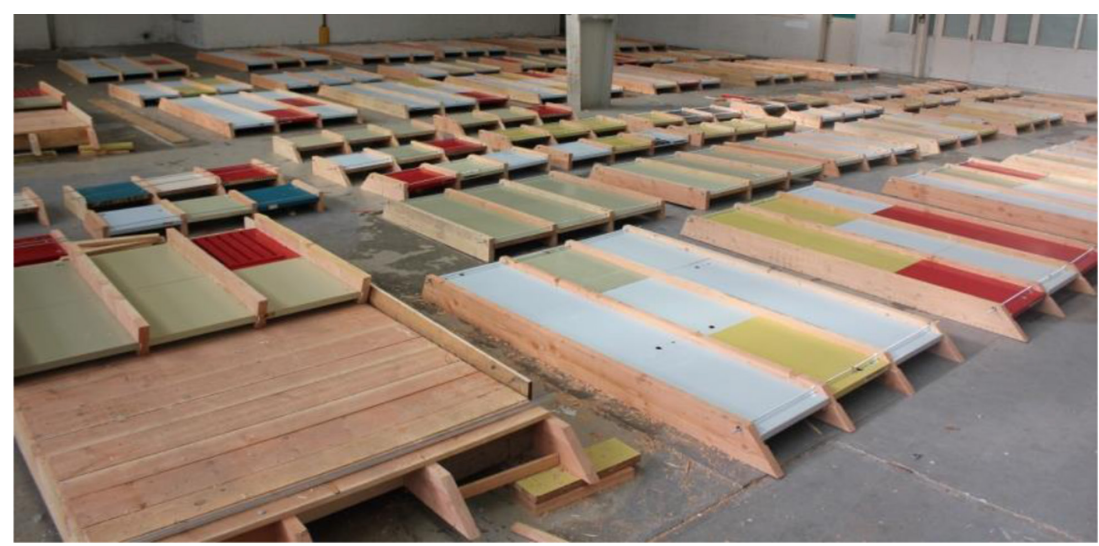

Figure 5: Structures are composed of five elements made from old doors.

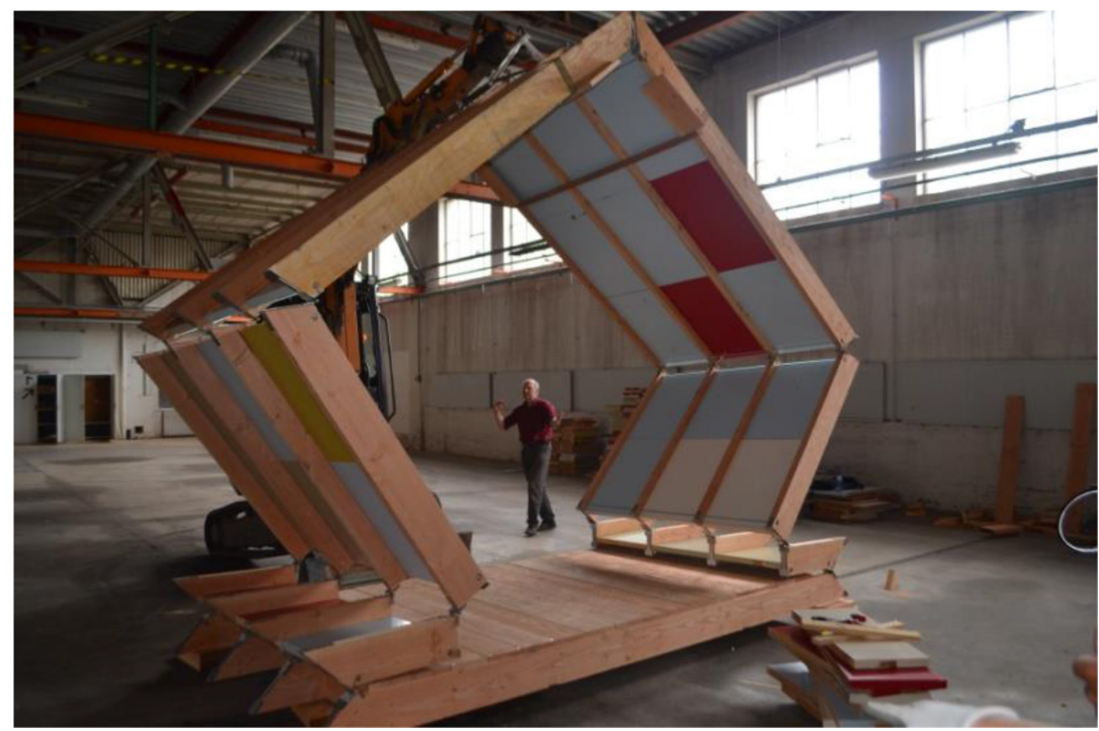

Figure 6: Foldable structure. 


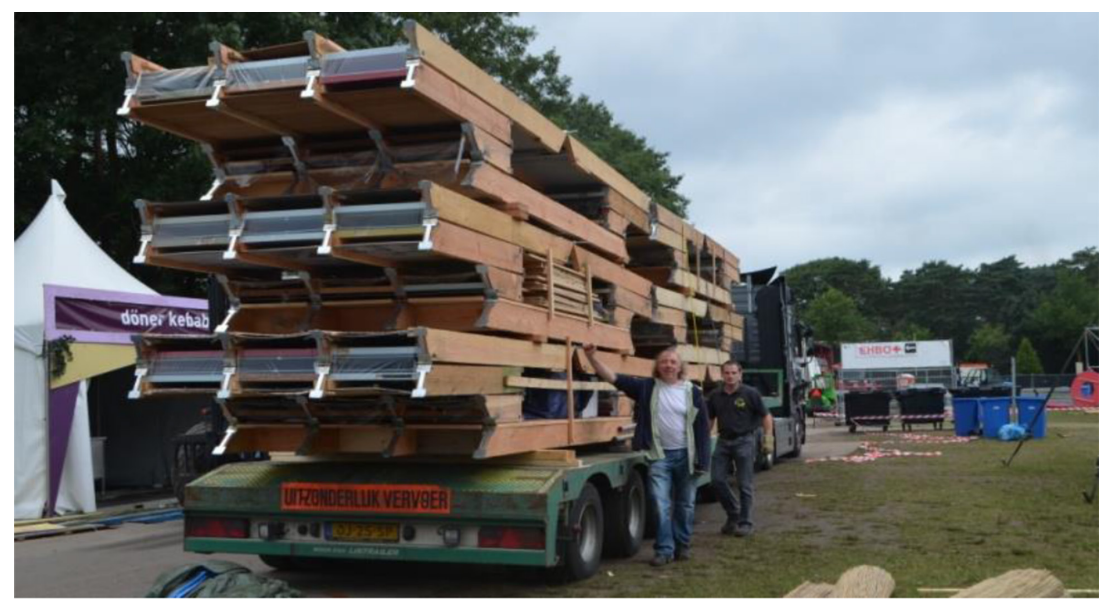

Figure 7: The foldable structures reduces transport load.

foldable structure is transported to a festival site (Fig. 7), where a tower of scaffolding is made. Together with a number of folded out structures makes the Summerlabb pavilion.

\subsection{Tower, showing different uses of existing materials}

The centre of the pavilion is a tower that makes a rising shape and holds up some of the structures with the archetype shape. The tower is made by scaffolding. This choice is to express the idea of reusing materials, since the same scaffolding can be used afterwards on construction sites without adjustments to elements.

\subsection{Foldable structures}

The pavilion is developed on the basis of 'folding houses' by using hinged panels (Fig. 6). The initial reason to make the structure foldable is to simplify setting-up the pavilion for a festival and to take it down when the festival is over. Yet, this is not the only ground. Folding out a structure of this size provides a good opportunity to emphasize the importance to reduce transport load, since a folded structure enables to stack more structures on one truck. In this way the transport emissions can be reduced.

The hinged structures are an effective means to point out that building industry is a source for high volumes of traffic due to frequent moving materials with many people working on site. By showing a full-size structure that folds to reduce its volume during transport can bring this issue to a festival in a playful means as one of the many aspects of sustainability (Fig. 7).

Reducing transport is an important issue in sustainable building, as about $25 \%$ of all transport is related to the construction and building industry.

\subsection{Local wood}

The main structural material is timber (Douglas fir). In total $38 \mathrm{~m}^{3}$ was needed for the 18 houses. In order to reduce transport load and carbon food print local wood from nearby forestry was used. This feature is an additional illustrative example of how to reduce transport load. 


\subsection{Reclaimed timber}

Another way that is used in the pavilion to show the diversity of sustainability is the application of reused timber, recovered from demolition projects. When irregularities in waste beams, such as nails, screws, et cetera are removed, and after re-sawing, the old wood becomes as new. The 'scars' that come from removed rusty mails and also the indents of removed screws improves the appearance of reclaimed timber rather than degradation.

\subsection{Reclaimed panels (re-using old inner doors)}

The pavilion shows that reclaimed materials from demolition can be used as building materials in new structures, for example using old interior doors. Re-using timber based materials from demolition keeps carbon enclosed in the material, instead of emitting $\mathrm{CO}_{2}$ through incineration. Emphasizing on waste reduction is important as about $35 \%$ of the total waste production comes from the building industry.

\section{6 plastic}

The pavilion shows a remarkable new use of recycled plastic. Upgrading plastic waste at low temperatures makes a colourful material. This application shows that reusing waste can create an appealing result (Fig. 8). The enthusiasm of visitors at festivals for such novel and sustainable application of waste material shows that such application makes the public more aware to recycle plastic waste.

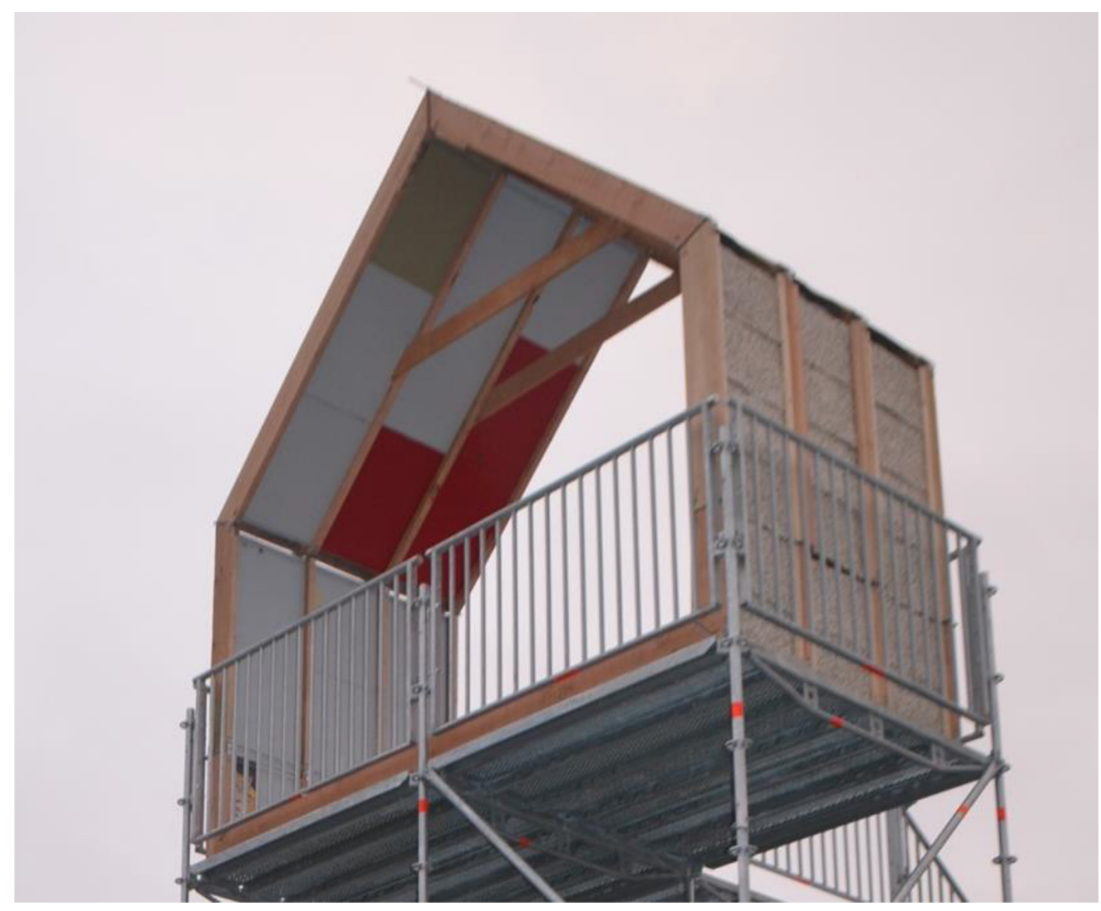

Figure 8: Outside: recycled colourful plastic; inside: old inner doors. 


\subsection{Sustainable roofing materials}

The various structures of the Summerlabb pavilion all have different roofing materials. Roof finishings are made for example, of bio-based materials, bio-degradable materials, modified wood (to extend the life span of low grade timber), and reclaimed timber from demolition.

\subsection{Example to reflect on reuse in a pleasing style}

Several of the structures are cladded with a surprising metal material: reused aluminium from off-set presses. These thin aluminium sheets are needed to print newspapers et cetera but can only be used once in the printing industry. Normally, used off-set sheets are recycled by melting this as addition to new aluminium. However, when cut to the needed sizes, the offset sheets can be well applied to form an appealing result of an overlapping slated-like roof. The shiny aluminium surface is in itself remarkable, the impression in monocolour ink of old newspaper articles makes its appearance even more striking (Figs 9 and 10).

\subsection{Special use of outdated advertising banners and old truck tarpaulins}

The structures with the archetype shape are designed without a front and back façade to emphasize the typical shape of a Dutch house with a gabled roof. However, to protect the Summerlabb partners with their expensive exhibition materials from rain and wind requires a flexible enclosure. Figure 11 shows this flexible layer made from reshaped advertising banners that are no longer usable or old truck tarpaulins or canvas that needs to be replaces. With this material, a kind of oversized curtain was made by cutting the fabric in suitable shapes and by sewing them back together. This heavy fabric proved to be an adequate 'façade': open in case of sunny days on a festival and closed on windy and/or rainy days according to user's needs and wishes.

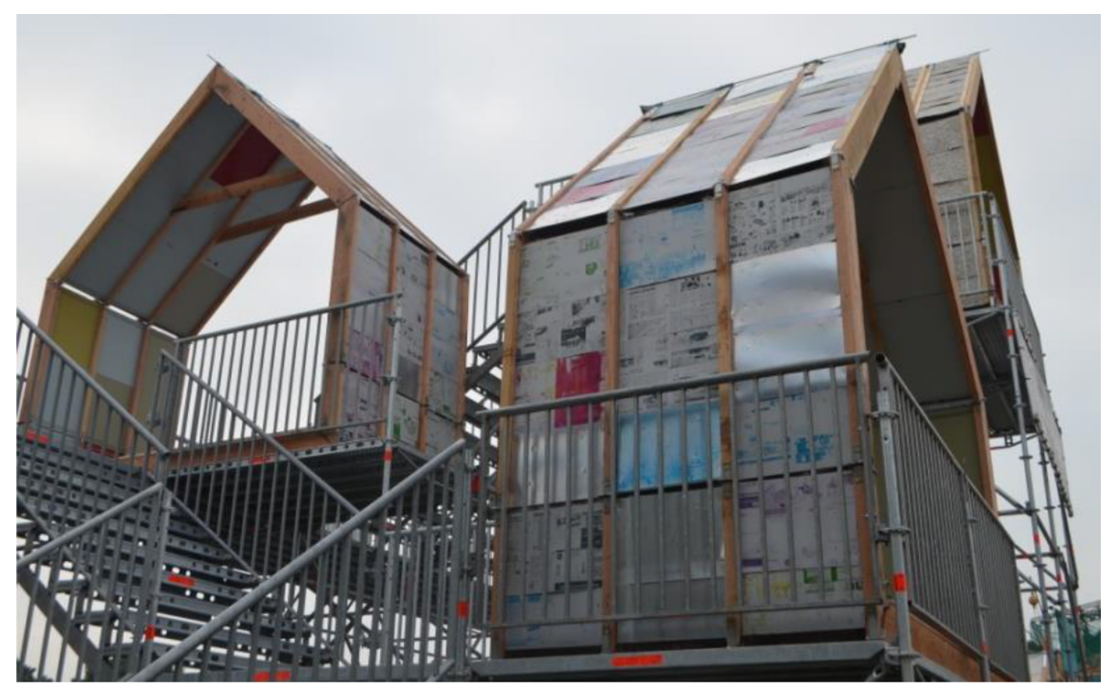

Figure 9: Shiny façade of reused aluminium from off-set press. 


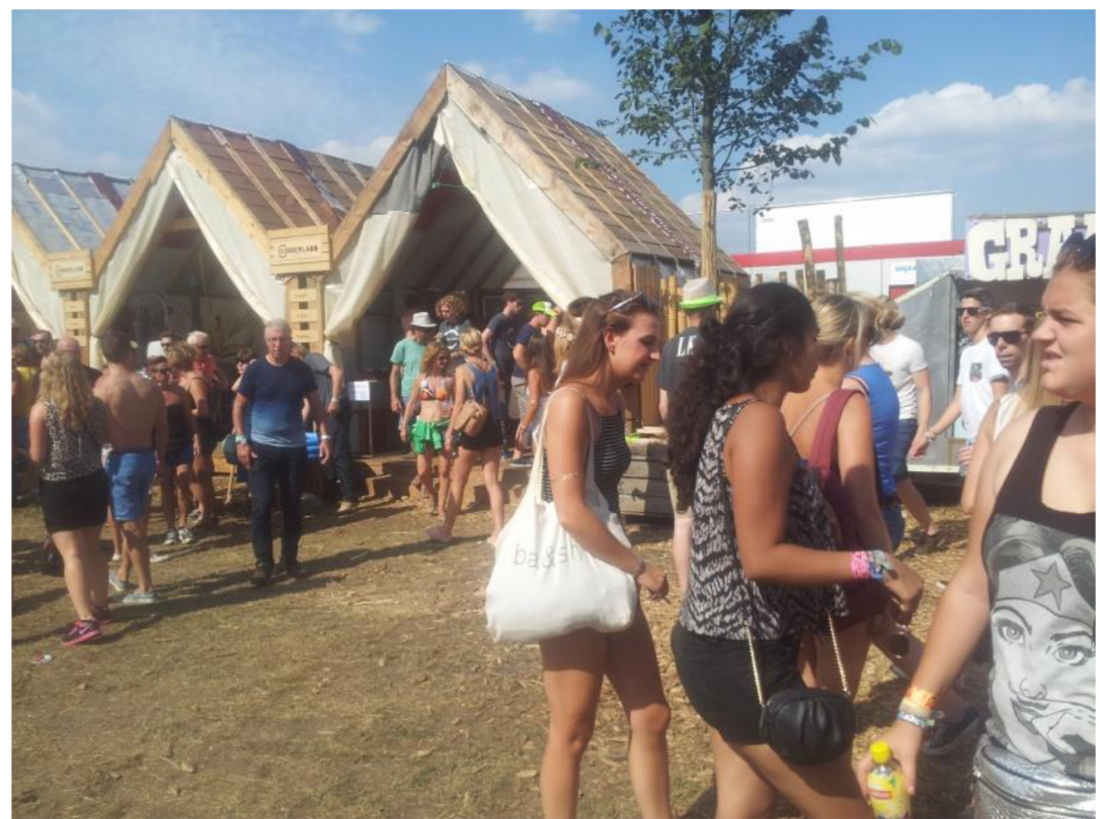

Figure 10: Structures to explain sustainability on festivals.

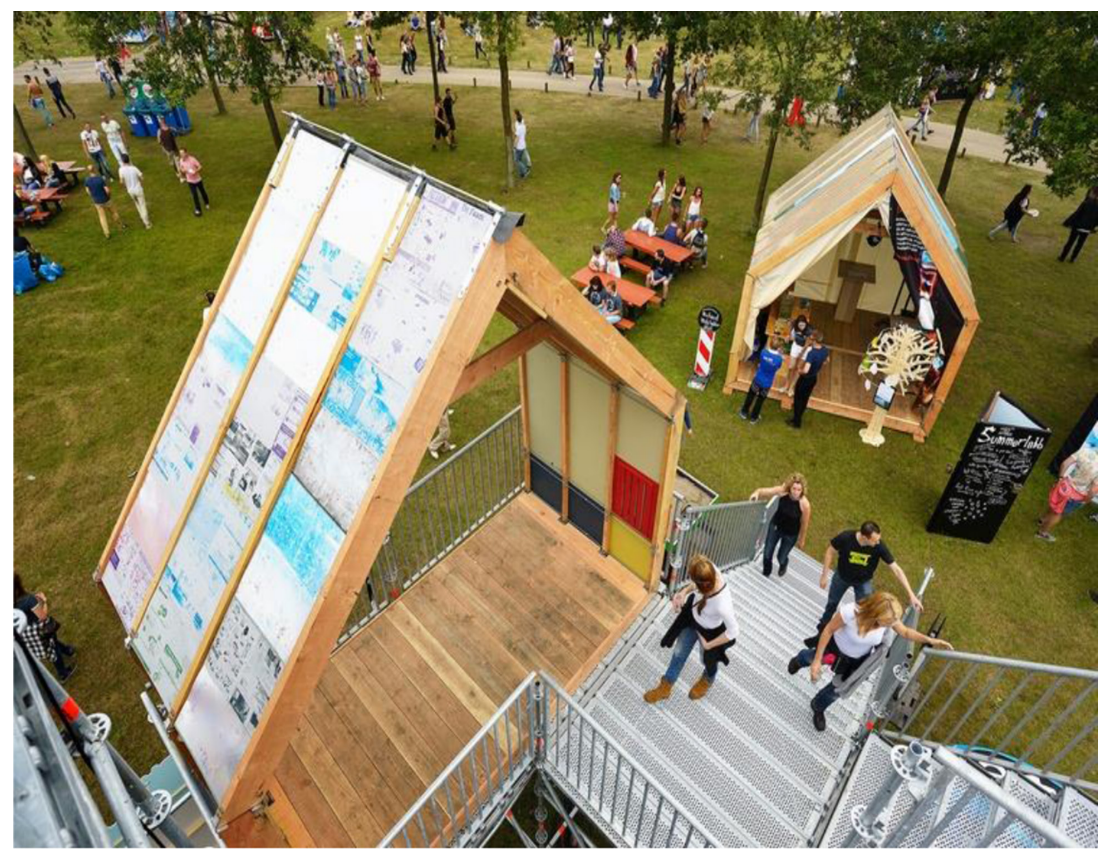

Figure 11: Curtain of reshaped advertising banners (Pukkelpop-2015). 


\section{CONCLUSION}

This cases study is an example of a motivation assignment of a concrete task that was actually built. In cooperation with a third party, students designed a concept, made technical drawings and calculations of a foldable structure and arranged the construction process. In total 18 structures were realized as itinerant pavilion for festivals and events in which the Summerlabb organization can offer an adequate platform to a number of up to 30 participants to promote sustainable innovations, to create awareness of sustainable concepts, and to explain and educate the importance to society to reduce, recycle and reuse waste.

The pavilion not only provides a stage for partners of Summerlabb to exhibit sustainable innovations, but is also a showcase on sustainability in itself for sustainable building. The ensemble of the pavilion does this by exhibiting facets of sustainability on full-scale with bio-based materials, reusing waste, reducing transport by foldable structures and using local available timber, reclaiming materials and much more in a pleasing, playful way to attract attention to sustainable developments in the building industry. Although the primary goal of the students' project was in different aspects of education, the pavilion is also an adequate platform and stage to explain and to educate on large-scale festivals.

\section{REFERENCES}

[1] Veeger, T. \& Moonen, S., Various challenging students' assignments: cases of creations realized on festivals and events. In Integrated Design International Conference (ID@50), Bath, 2016.

[2] Schie, F.V., Janssen, A., Doornbosch, M., Moonen, S., Veeger, T. \& Kindt, R., STW DesignPrijs 2014, Utrecht: Technologiestichting STW, available at: www.stw.nl/sites/ stw.nl/files/jaarverslagen/Jaarverslag-2014_0.pdf, 2014.

[3] Hout-Centrum, "Summerlabb - 1e Prijs Wood Challenge 2014 (in Dutch)," 2014, [Online], available at: www.woodchallenge.nl/summerlabb.

[4] Summerlabb, SummerLabb: hét lab van festivalland! summerlabb, 2015, [Online], available at: www.labbsessies.nl/summerlabb/?page_id=727.

[5] Stichting-Summerlabb, Summerlabb comunity, Summerlabb, 2014, [Online], available at: www.facebook.com/summerlabb/timeline?ref= page_internal.

[6] Double2, "Aftermovie: Summerlabb op Wereldhavendagen 2014," Double2, 2014, [Online], available at: www.d2bv.nl/site/aftermovie-summerlabb-op-wereldhavendagen-2014/.

[7] Doornbos, M., Fire safety in pavilion Summerlabb: required safe time versus available safe time, Eindhoven University of Technology, Eindhoven, 2014.

[8] studio040, TU/e-studentes maken inklapbaar paviljoen voor festivals, 2014, [Online], available at: http://www.studio040.nl/nieuws/24380-tue-studentes-maken-inklapbaarpaviljoen-voor-festivals.html.

[9] The Summerlabb Pavilion| the making of, available at: https://www.youtube.com/ watch? $\mathrm{v}=$ N69T-XcsKtA. [Film]. the Netherlands: Eindhoven University of Technology / Double2, 2016.

[10] Summerlabb | Extrema Outdoor 2014, available at: https://www.youtube.com/ watch?v=9DFvHZkDteE. [Film]. the Netherlands: Double2, 2014. 